\title{
The seed testing station's role in the testing of fungicides
}

\author{
J. de Tempe
}

Official Seed Testing Station, Wageningen, the Netherlands.

Received: 20 December 1971

\section{Summary}

The present situation of fungicidal seed treatment and the seed testing station's task in screening new fungicides are discussed.

Methods are mentioned and special attention is given to the difficulties encountered in soil tests with fungicide-treated seeds. There may be other factors restricting disease beside fungicide treatment and non-characteristic symptoms of seedling blight may be partly due to soilborne fungi. Hence interpretation of soil test data is difficult.

At present better results against non-basidiomycetous seedborne infections are often obtained with carbamate-type fungicides than with most of the new compounds that are not yet commercially available. Future developments will probably change this situation.

\section{Introduction}

In the Netherlands the Official Seed Testing Station has the facilities and experience and usually can provide suitable seed samples for screening seed treatment fungicides. New and promising products are received from the chemical industries, who pay for the tests. Laboratory tests for seed health on blotters or on agar are normally used. When soil tests in non-sterile soil are made, conditions must be adapted to the kind of seed and pathogen concerned, so that as much disease can be observed in the aerial plant parts as possible. Most important are the right kind of soil and appropriate temperature. Field trials are only exceptionally made.

The chemical industries usually prefer their products to be tested on cereal seeds, but it may be interesting for the seed testing station to study the reaction of less important infections, for instance in vegetable seeds.

\section{General considerations}

Two types of fungicide for seed treatment have been known from long ago. The organic mercurials are best as seed disinfectants because they are volatile and water-soluble. Due to their volatility they have a disinfecting action against the not too deep-seated seedborne infections when the seed is still dry. Therefore it is advisable to store the seed for at least a few days between mercurial treatment and sowing. Superior protectants are substances such as thiram and captan, which are non-volatile and hardly soluble. They do not penetrate into the seeds and will not kill infections in the seed tissues 
but only act as contact fungicides. But after sowing of the seed in soil they do not disappear quickly as the mercurials do, so that they afford protection to seed and seedling against semi-parasitic soil micro-organisms throughout the sensitive emergence stage. The properties required for a good disinfective and a good protective activity are contradictory and cannot be combined in a single substance. Also attemps to mix substances with complementary effects have not been very successful.

New possibilities were offered by the systematic fungicides. When inside the plant tissues, these may act both as a disinfectant against internal infection and a protectant against external invasion. These possibilities have not yet been fulfilled as far as seeds are concerned.

Notable are the oxathiines (vitavax, plantvax). Vitavax (carboxin) can be succesfully used as a disinfectant against seedborne loose smut of barley and wheat, as well as for protecting a young bean crop, grown from treated seed, against invasion by fieldborne bean rust. The restriction of these compounds is that they are mainly active against Basidiomycetes whereas the majority of seedborne diseases are caused by Ascomycetes and Fungi imperfecti. Substances are needed with a broader spectrum, or with a similar activity against those other groups of fungi.

The ideal products should be active against fungi and not against higher plants and animals other than insects. In several countries the chitin synthesis is now studied, which is characteristic for fungi (apart from the Phycomycetes) and insects (Dekker, 1971). Substances interfering only with chitin synthesis might be attractive pesticides.

The present situation is still far from ideal. Mercurial fungicides are broad-spectrum poisons, capable of coagulating all proteins and inactivating all enzymes. So they are also active against higher plants and animals including man. When used for seeds, their activity is directed against the micro-organisms as these are more or less exposed and have a relatively large surface. But phytotoxic effects may be observed with cereal seeds raised in moist climates and with other sensitive kinds of seeds. Nowadays the use of mercurial fungicides on seeds is being restricted because of their toxicity to seed-eating birds and consequently to the birds of prey. Also cases are known of death due to mercury poisoning of workers who treated seed lots with mercurials or stayed in rooms where treated lots were stored, or who continually examined mercurial-treated seed samples for purity in the laboratory.

In 1958 , I studied the phytotoxic effect of routine mercurial treatments on cereals in field trials. For disease-free wheat and barley the decrease in emergence and yield could amount to more than $10 \%$. Hence, when no production of sowing seed was intended, so that the crop would not be inspected in the field with the change of it being turned down by the certifying agency because of Tilletia spp. (bunt) in wheat or Drechslera graminea (stripe disease) in barley, it was preferable to treat the sowing seed with thiram. Then control of seedborne pathogens is less complete but protection against soilborne semiparasites is better and there is no phytotoxicity. This was reflected in increased emergence and yield figures. Nowadays there are more attractive alternatives for mercury than thiram.

Another argument against the mercurials is that in recent years they failed against seedborne Drechslera avenae (leafspot of oats) (Noble et al., 1966). Since mercury resistance of the fungus was first observed the non-resistant parent form was gradually replaced in certain countries under the pressure of continued mercurial seed treatment. Simultaneously infection percentages in oat seed samples increased enormously. Also, by means of seed trade the resistant strain spread all over the world. However, acquired resistance can be expected to be more frequent with selective fungicides. 


\section{Examples}

In my laboratory, the main cereal seed infections against which fungicides are tested are those by Fusarium, Drechslera and Septoria spp. Some attention is paid to Phoma betae (black leg) in beets and Botrytis cinerea (grey mould) in flax, and occasionally to Plenodomus lingam (black leg) of cabbage and Stemphylium radicinum (black rot) and Alternaria dauci (leaf blight) of carrots. In spring, field trials are made with Ustilago nuda (loose smut) in barley. Experiments in vitro with the fungi are not carried out. Naturally infected seed samples are always used and conclusions are not based on the perhaps exceptional reaction of a single sample. Not always a close agreement is observed between infection figures obtained on more or less sterile laboratory substrates and disease percentages observed in non-sterile soil. When occurring such an agreement should be regarded with caution, for in natural soil disease-reducing factors may be active, the main one being antagonism eliminating the pathogen in or on slightly infected seeds, and also disease-increasing factors such as the activity of semi-parasitic soil micro-organisms invading weak seeds under adverse emergence conditions. In addition other seed-borne infections than the one studied can be a source of error. Insufficient uniformity of the medium will further decrease the reliability of soil test results.

The uncertainty of seedling blight observations in soil tests can be illustrated with some recent experiments. In a laboratory blotter tests nine Fusarium-infected wheat seed samples had an average of $37.4 \%$ infection, which by two fungicide treatments was reduced to 8.7 and $4.8 \%$, respectively. In a soil test at $12^{\circ} \mathrm{C}$, emergence was above $90 \%$, with a disease percentage of 38.7 for untreated and of 10.7 and 4.2 for the two treatments. The agreement between laboratory and soil test seems quite convincing, but for the non-treated samples the correlation coefficient between laboratory and soil test figures was only 0.70 , which suggests that the infection studied was not responsible for all of the disease observed.

For fifteen Drechslera avenae-infected oat seed samples, treated with two fungicides each in a lower and a higher dosage, the average infection in the laboratory amounted to $53.7 \%$ untreated and $2.4,1.3,4.5,1.9 \%$ for the four treatments. The corresponding disease averages in a $7^{\circ} \mathrm{C}$ soil test were 51.6 and $20.8,13.9,22.7,20.2 \%$. For the untreated samples the correlation coefficient was only 0.56 . For the treated samples it could not be decided whether the high disease levels in soil were caused by a decreased effect of fungicides in the soil medium or by the activity of soilborne semi-parasites. In another experiment with oats laboratory averages were $79.4 \%$ for non-treated and 1.4 , $29.1,18.3 \%$ for three treatments, with the disease averages in soil being 68.6 and 22.9 , $69.2,22.8 \%$. So again the disease percentages in soil were much higher than the infection percentages observed in the laboratory test for the treated samples. The results suggest that treatments which are unsatisfactory in the laboratory can be still more so in soil.

In an experiment on Plenodomus lingam in cabbage seed, five samples with an average infection of about $20 \%$ were used. In peaty soil at about $20^{\circ} \mathrm{C}$ the untreated samples had an average of only 7.6\% seedling blight. The plantlets with post-emergence damping-off were brought to the laboratory and placed on moist blotters under near-ultraviolet light. More than half of these, viz $4.7 \%$, produced Phoma pycnidia. The low percentage of identifiable Phoma infection may be caused by pre-emergence damping-off escaping detection, or by delayed development of disease escaping observation in the short-duration experiment. Also the pathogen might be partly eliminated by soilborne antagonists. On the other hand it is suspicious that only part of the diseased 
seedlings produced pycnidia under laboratory conditions. This may again by due to soilborne micro-organisms or seedborne Alternaria spp. having contributed to the dampingoff, or to antagonists preventing Phoma infections to sporulate. In loamy sand disease percentages after seed-treatment were much higher than could be attributed to surviving infection. As moreover certain fungicides will be active against soilborne microorganisms and others not, it is not surprising that the agreement between laboratory and soil test figures often is not a close one. In fact, in this experiment in which 19 fungicides were compared, the observed agreement was disappointing.

From field trials on these diseases still less can be expected because of additional sources of error and limited possibilities of observation.

In general recent results with established fungicides not containing mercury, such as carbamates, have been more satisfactory than those obtained with quite new compounds. For instance, the performance of maneb-zineb mixture against Drechslera infections of cereal seeds is outstanding.

Field trials on cereal smuts can be very informative with Ustilago nuda in barley. In a 1971 trial 17 treatments were included, each sown in 4 rows of 200 seeds. In the heading stage the numbers of healthy and diseased ears were counted. Dr J. E. Boeke of our Station plotted a graph, in which the numbers of healthy ears per row were placed on the horizontal axis and the numbers of diseased ears (at a 10-fold scale) on the vertical axis (Fig. 1). The four points per treatment were indicated with the same

number of diseased ears

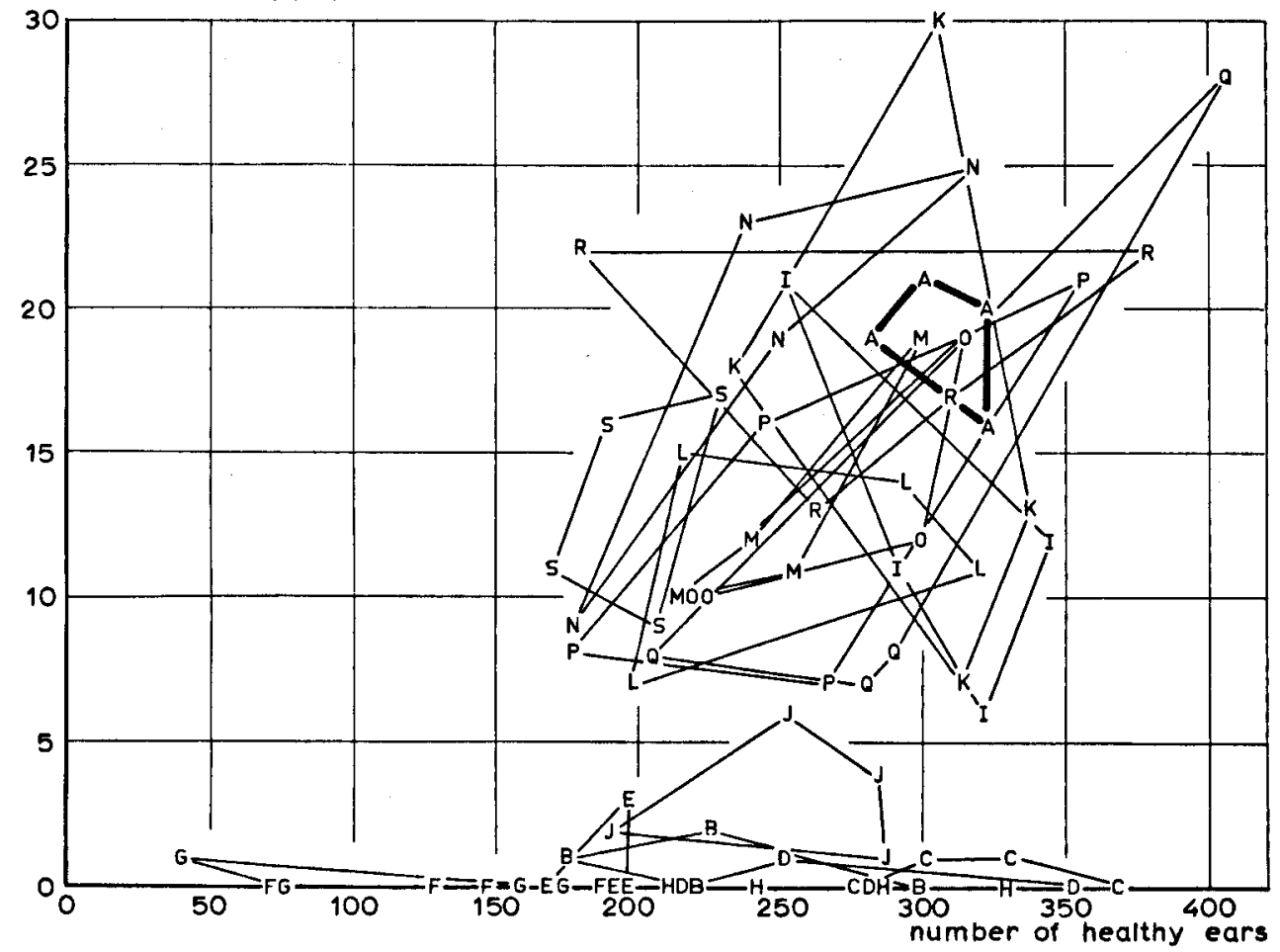

Fig. 1. Field trial on control of loose smut in spring-sown barley. 4 rows of 200 seeds per treatment. A. is untreated. 
letter and connected by lines. It can be seen hat the treaments form two groups, of which the bigger one surrounds the untreated (A) which indicates that these treatments have not had the desired effect. The smaller group at the bottom of the graph includes the more effective treatments with a low number of diseased ears. Of these, G, F and $E$ have a rather low number of healthy ears, suggesting phytotoxicity. $B, C$ and $D$ are better; they contain carboxin. Only $\mathrm{H}$, a new product, was still more effective. With loose smut the difficulties restricting conclusions in case of seedling blights do not play a role.

\section{Conclusions}

It is not the intention of this paper to provide figures on the performance of certain fungicides, especially as many of the substances tried were only known by number. But it may be stated that so far the semi-classic carbamates are usually more effective when used against ascomycetous and imperfect fungal pathogens in cereal seeds than the newer, often systematic, fungicides. So these older fungicides should be further tried on cereals in combination with oxathiines or other compounds with an activity against smuts. In later stages of multiplication, when large quantities of seed have to be treated, one may rely on the effective smut treatment of an early stage and omit the expensive fungicide against smuts. Thus pollution of soil and water with superfluous chemicals is avoided.

The search for substances with a selctive activity against non-basidiomycetous fungi, both seedborne and fieldborne, or active against fungi in general, should be continued. Systematic fungicides might become useful against certain seedborne infections, which are difficult to control and of which traces can be dangerous.

\section{References}

Dekker, J., 1971. Resistentie tegen fungiciden. Gewasbescherming 2: 97-108.

Noble, M., Q. D. MacGarvie, A. F. Hams \& E. L. Leafe, 1966. Resistance to mercury of Pyrenophora avenae in Scottish seed oats. Pl. Path. 15: 23-28.

Tempe, J. de, 1958. Three years of field experiments on seedborne diseases and seed treatment of cereals. Proc. int. Seed Test. Ass. 23: 38-67. 